\title{
A brief review: basic coil designs for inductive power transfer
}

\author{
Nadia Nazieha Nanda ${ }^{1}$, Siti Hajar Yusoff ${ }^{2}$, Siti Fauziah Toha ${ }^{3}$, Nurul Fadzlin Hasbullah ${ }^{4}$, \\ Amelia Shafina Roszaidie ${ }^{5}$ \\ 1,2,4,5 Department of Electrical and Computer Engineering, International Islamic University, Malaysia \\ ${ }^{3}$ Department of Mechatronics Engineering, International Islamic University, Malaysia
}

\begin{tabular}{l} 
Article Info \\
Article history: \\
Received Apr 1, 2020 \\
Revised Jun 21, 2020 \\
Accepted Jul 20, 2020 \\
\hline Keywords: \\
basic coil designs \\
dynamic wireless charging \\
(DWC) \\
electric vehicle (EV) \\
inductive power transfer (IPT) \\
power transfer efficiency (PTE) \\
static wireless charging (SWC) \\
wireless power transfer (WPT)
\end{tabular}

\section{Corresponding Author:}

Nadia Nazieha Nanda,

Department of Electrical and Computer Engineering, International Islamic University Malaysia,

Jalan Gombak, 53100 Kuala Lumpur, Malaysia.

Email: nnazieha.nanda@gmail.com

\begin{abstract}
The inductive power transfer (IPT) has contributed to the fast growth of the electric vehicle (EV) market. The technology to recharge the EV battery has attracted the attention of many researchers and car manufacturers in developing green transportation. In IPT charging system, the coil design is indispensable in enhancing the EV battery charging process performance. This paper starts by describing the two charging techniques; static charging and dynamic charging before further presents the IPT system descriptions. Afterwards, this paper describes a brief review of coil designs which discusses the critical factors that affect the power transmission efficiency (PTE) including their basic designs, design concepts and features merits. The discussions on the basic coil designs for IPT are of the circular spiral coil (CSC), square coil (SC), rectangular coil (RC), and double-D coil (DDC). Furthermore, the significant advantages and limitations of each research on different geometries are analyzed and discussed in this paper. Finally, this paper evaluates some essential aspects that influence the coil geometry designs in practical.
\end{abstract}

Copyright $\odot 2020$ Institute of Advanced Engineering and Science. All rights reserved.

\section{INTRODUCTION}

Wireless power transfer (WPT) system is using the power transmission coil principle to transfer the electric power from the primary grid source to energize the electric vehicle (EV) [1]. The implementation of the WPT system to the EV has hugely evolved after the issue related to the depletion of energy resources especially petroleum started to get global attention besides the fact that petroleum gas emission has contributed to air pollution [2]. Fortunately, this arising issue is supported by the willingness of car manufacturers to be involved in this technology. There are different approaches to WPT, such as the capacitive coupling, inductive coupling, and magnetic-resonance coupling [3]. Capacitive coupling relies on the coupling of two plates that produce the electric field. The alternating voltage of transmitter plate will create the electrostatic field on the receiver plate causes by the induced EMF from the oscillating electric field [4]. The capacitive coupling can be used only for low power applications, such as drone charging or mobile charging, and this approach is obviously less suitable for charging the EV [5, 6]. However, this approach might be able to be implemented for EV if a proper design of a compensation network is utilized [7].

Meanwhile, in IPT, the field created from the coupling of the two coils; transmitter (primary) coil and receiver (secondary) coil, is referred to as the magnetic field. The magnetic field produced results from obeying the Ampere's Law and Faraday's Law [8]. The source generates an alternating current that creates an oscillating magnetic field at the transmitter coil. The magnetic field produced is then passed through to the receiver coil and thus produced the induced alternating current to flow in the load of the circuit, which commonly is the EV's battery. For the magnetic-resonance coupling, it uses the resonant principle where it allowed the coupling 
between coils to occur in several centimetres gap. The alignment flexibility and power transmission efficiency (PTE) for this approach are higher compared to the capacitive and inductive coupling $[9,10]$.

However, only the inductive coupling principle has extensively applied to not only EV but also to supply power to household appliances, biological implants and other means of transportation such as buses and shuttle vehicles [11-14]. Currently, most researchers are focusing on the PTE, coil geometry, coupling coefficient, misalignment tolerant and air-gap between the coupling coil [15-17]. The focus of this paper is to briefly discuss the basic coil geometry designs of the IPT system for EV, which applied either to the static charging or dynamic charging. Countless studies are executed on different geometries to guarantee good coupling even in conditions of misalignments. Since there is no discussion yet related to the basic coil geometry designs, especially for EV, therefore, this brief overview will investigate several commonly used geometry designs for EV application that usually concern about the cost. With that, no discussions on other coil geometries such as E-type, U-type, W-type, I-type and S-type will be discussed here as these geometries dominate the use of ferrite, which lead to higher cost. The evaluation of coil geometries here is mainly on the circular spiral coil (CSC), square coil (SC), rectangular coil (RC) and double-D coil (DDC). The key parameters affecting the overall system, together with the advantages and limitations, are also discussed in this paper.

\section{STATIC AND DYNAMIC CHARGING}

EV technology is well-known in the vehicle industry since the early 1900s [18]. This technology has recently become one of the ultimate solutions on utilizing the electric power source, which is known to be environmentally friendly compared to the conventional internal combustion engine. The emergence of this technology arises from the existence of the plug-in static charging. The existing plug-in conductive charging requires physical contact between the electric power source and the vehicle battery. This method has become less compatible as it causes inconvenience and requires cable to supply the electric power to the EV. To be widely accepted by the public, researchers and car manufacturers have put tremendous effort into producing a convenient and safe method to charge the EV. Therefore, the static wireless charging (SWC) introduces the charging process without any presence of cables. It offers compactness and safety due to charging capability without any use of a cable. Additionally, the efficiency could reach up to $91 \%$ over 25.4-centimeter air-gap [8]. Figure 1 illustrates the typical structure of the static wireless charging (SWC) of the WPT system. As the years pass, researchers started investigating the dynamic wireless charging (DWC). This idea is due to the time taken to fully charge an EV which approximately took 4 hours with the $3.7 \mathrm{~kW}$ of EV charging rate when using the SWC technique [19]. The DWC technique proposed to enable the EV charging process to occur while the vehicle is in motion without the need to stop and park at the designated charging station. However, the SWC is still reliable at places such as office areas or residential areas where the vehicle is parked for some quite amount of time before starting the engine again. The basic idea of wireless charging for the EV while the vehicle is parked is illustrates in Figure 1.

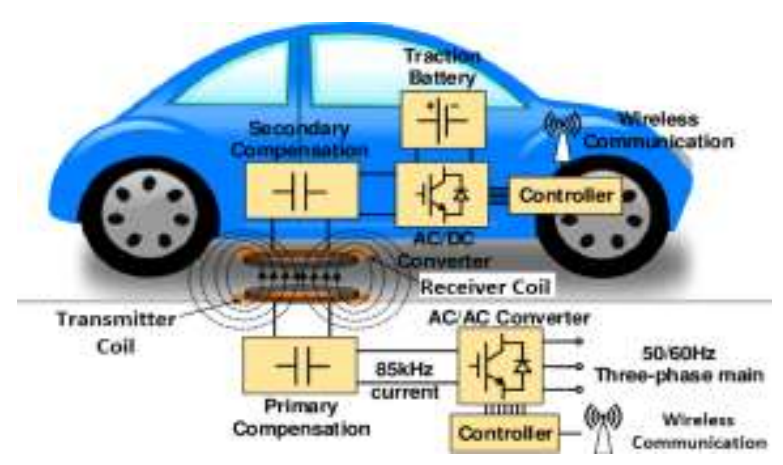

Figure 1. Basic wireless charging structure [20]

Figure 1 shows the primary AC voltage converted through an AC-AC power converter with an operating frequency of $85 \mathrm{kHz}$. The operating frequency range starts from $10 \mathrm{kHz}$ to $100 \mathrm{kHz}$ for the WPT system to be working. Despite this, the operating frequency, as stated in SAE J2954, is limited to $85 \pm 3.7 \mathrm{kHz}$ for $\mathrm{EV}$ [21]. The AC voltage is then transmitted to the transmitter coil after passes through the primary compensation in which the transmitter circuit system embedded in the ground with the primary compensation 
network. The receiver coil then receives the energy that is transmitted by the transmitter coil on the receiver side. The power received is then pass through the secondary compensation before it is being converted to DC voltage to be used to recharge the EV battery. The transmitter and receiver coils made up of several coil geometry designs depend on the magnetic field distribution desired for the system's application. Now, imagine the same concept as before being implemented, but the difference is that the car is in motion. This concept refers to DWC. DWC will happen when the receiver coil attached underneath the EV charges through the magnetic field between several transmitter coils (commonly embedded in the ground). DWC has a design that could reduce the range anxiety and time-consume to charge due to the range limitation that arises from the SWC of EV. However, when considering the DWC, the misalignment between the transmitter and receiver coils is a major concern. An increase in misalignment could reduce the coupling coefficient and thus reducing the mutual inductance and PTE of the system.

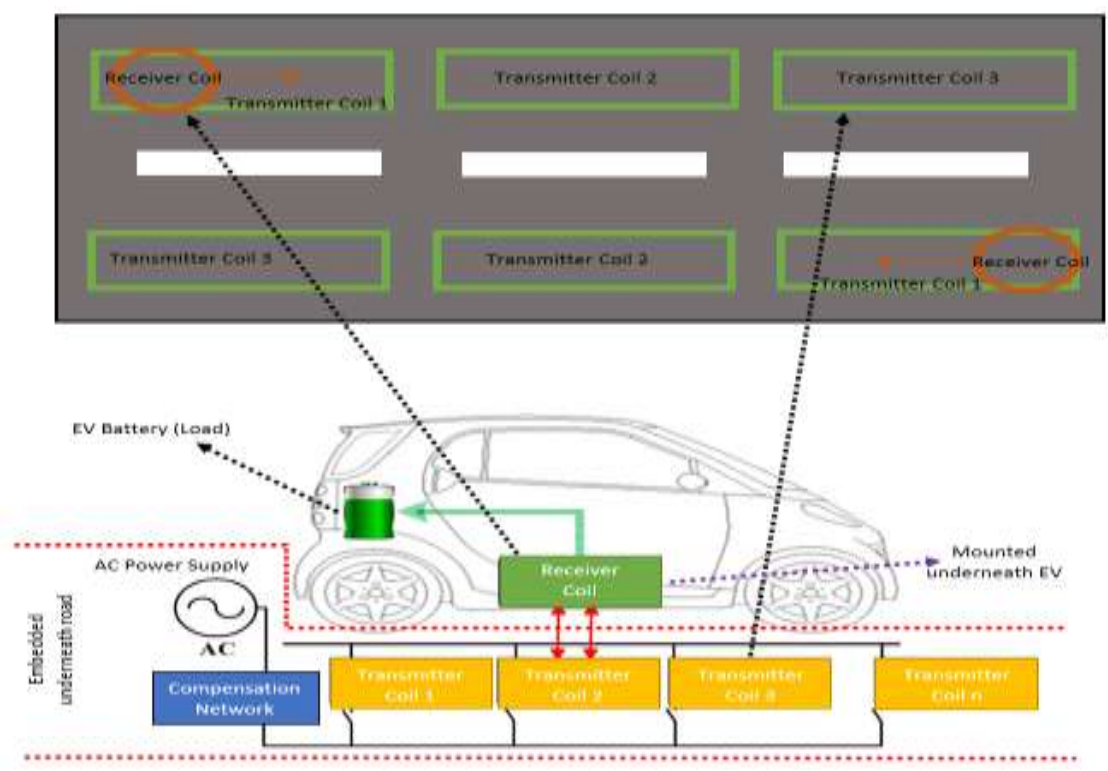

Figure 2. Schematic of multiple transmitter coils and single receiver coil in DWC system [22]

The misalignment may highly occur because of the movement of the receiver coil from one transmitter coil to another transmitter coil along the track, as shown in Figure 2. The main idea of this technique is simple where multiple primary coils called transmitter coils embedded in the ground requires to transmit the electric power from the grid to the secondary coil called receiver coil mounted at the bottom of the vehicle. There is no physical or mechanical contact between the two coils and the distance between the transmitter and receiver coils is referred to as ground clearance or typically, air-gap. As the receiver coil passes one of the multiple transmitter coils, the transmission of power has expected to occur from one transmitter coil to the next transmitter coil. The transmitter coils are placed along the road as it needs to be able to transfer power wirelessly in-motion $[8,23]$. In simple words, the transmitter and receiver coils will be switched on and off dynamically depending on the EV position.

\section{PARAMETERS AFFECTING THE IPT SYSTEM PERFORMANCE}

Typically, the IPT system consists of not only the suitable coil geometry to create the electromagnetic induction but also consists of suitable compensation topology (CT). Different CTs choices can apply to different areas of application. The electromagnetic induction created by the coupler does not imply that all flux from the transmitter coil gets linked to the receiver coil [8] the losses of the flux result in a phenomenon called flux leakage. However, the unwanted event could be avoided with the use of a CT that applied the capacitors to compensate for the IPT circuit system. Also, the minimization of power supply VA rating will be possible; thus, it leads to maximum PTE. There are four basic CTs which either made up of series-series (SS), seriesparallel (SP), parallel-parallel (PP), or parallel-series (PS) capacitors arrangements [24-26]. Not limited to that, the hybrid CTs have also been reported including LCC-LCC, LCL-LCL, LCC-P, LCL-P, S-CLC, LCL-S, CCL-S and multi-LCC capacitors and inductors arrangements [27]. The CT is chosen based on the suitability 
of the designed system and its application. Based on several studies, the most popular CTs are the SS and LCCLCC topologies due to their suitability and flexibility to optimize the high frequency to obtain the desired PTE. Besides the fact that their transmitter capacitances being independent towards the load which make both CTs best suited for not only SWC but also DWC, where the relative position of transmitter coil is changing concerning the receiver coil's position [24, 26, 28, 29].

Figure 3(a) demonstrates the SS topology. This topology is suitable in fulfilling different utilities' preferences of the IPT system. The SS topology is chosen not only in static charging but also in dynamic charging [27]. Previous research has proven that this CT is suitable for the long-track application [3, 25, 30]. Meanwhile, Figure 3(b) shows the LCC-LCC topology. This topology can achieve zero current switching, which means that the reduction of current stress in the inverter is possible by tuning this CT. Previous research has proven that this CT has a high tolerance to misalignment and independent of load [28, 31]. Other CTs are not discussed in detail in this paper.



(a)

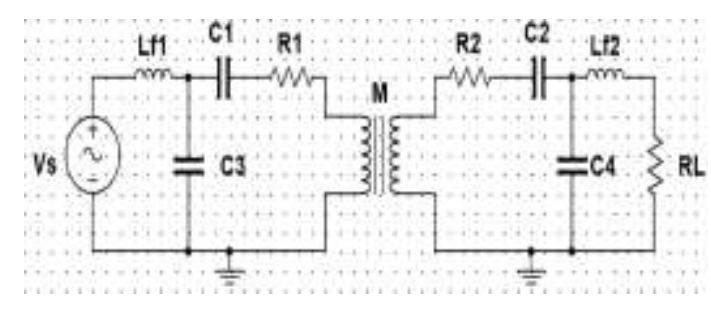

(b)

Figure 3. (a) Basic series-series and (b) Hybrid LCC-LCC compensation topologies

The topologies, as mentioned earlier, mainly comprise of both transmitter and receiver circuits. R1 and $\mathrm{R} 2$ represent the resistance of the transmitter and receiver coils, respectively. $\mathrm{C} 1, \mathrm{C} 3$ and $\mathrm{C} 2, \mathrm{C} 4$ are the compensation capacitors of the transmitter and receiver coils, respectively. Compensation capacitors compensate the inductances of the IPT system so that the system can operate at the designated operating frequency. RL refers to the load, which in this case is the EV battery pack that acts as the EV charging system, and it directly connects to the receiver coil [32]. RL, which is the simplified resistor, may also be representing the driving system or rectifier [8]. The overall circuit works by transferring power from the transmitter coil to the receiver coil in which produces the magnetic field when the two coils (L1 and L2) respectively are coupled together. The higher the coupling coefficient, the higher the mutual inductance $(\mathrm{M})$ thus increasing the power transmission. These are the key factors that determine the efficiency of the overall IPT system. Equation (1) is the formula to determine $\mathrm{M}$ and the relationship between power and mutual inductance, $\mathrm{M}$ is determined by equation (2) [33]:

$$
\begin{aligned}
& \mathrm{M}=\mathrm{k} \sqrt{ }\left(\mathrm{L} \_1 \mathrm{~L}_{-} 2\right) \\
& \mathrm{P}=\mathrm{M}^{\wedge} 2 / \mathrm{L} \_2 \omega \mathrm{I} \text { 1 } \mathrm{Q}
\end{aligned}
$$

where $\mathrm{k}$ is the coupling coefficient, meanwhile, L1 and L2 are the self-inductances of the transmitter and receiver coils, respectively. One of the essential parameters that need to be taken into account when dealing with the coupling coefficient is coil geometry as it is able to affect the coupling coefficient [22]. The mutual inductance, $\mathrm{M}$ will determine the amount of flux that will be passing through the receiver coil. Thus, the changes in coupling coefficient, $\mathrm{k}$ will affect the mutual inductance, $\mathrm{M}$ and output power, $\mathrm{P}$. I1 is the transmitter circuit current, Q is the quality factor of the receiver circuit, and $\omega$ is the operating frequency. The previous mentioned equations are generally for IPT system utilizing any CT for the system. For the IPT system to function very well, the power factor is desired to be unity. Therefore, Table 1 gives the efficiency of IPT system when using the SS $[25,26]$ and LCC-LCC [34, 35] topologies as follows.

Figure 4 illustrates the WPT equivalent circuit, which contains a converter at both the transmitter and receiver sides. The transmitter converter acts as the high-frequency current generator. Meanwhile, the receiver power converter acts as the rectifier to rectify the system once the power is delivered from the transmitter to the receiver coil [36]. A power converter is vital in boosting the efficiency of the system. The blue dotted line box in Figure 4 is the SS topology. The same equivalent circuit can use any other topologies that best suited to the application's goal. 
Table 1. SS and LCC-LCC topologies efficiency

\begin{tabular}{cc}
\hline Topology & $\frac{\text { Efficiency }}{R_{L}}$ \\
\hline Series-Series & $\frac{R_{L}+R_{L}+\frac{R_{1}\left(R_{2}+R_{L}\right)^{2}}{\omega_{0}^{2} M^{2}}}{\frac{k}{\left(\frac{L_{f 1}}{L_{1}}\right)\left(\frac{L_{f 2}}{L_{2}}\right)} *\left(\frac{U_{1} U_{2}}{\omega \sqrt{L_{1} L_{2}}}\right)}$ \\
\hline
\end{tabular}

where Lf1 and Lf2 are the compensated inductance for transmitter and receiver coils, respectively, mean while, $\mathrm{U} 1$ and $\mathrm{U} 2$ are the $\mathrm{AC}$ voltage for inverter and rectifier.

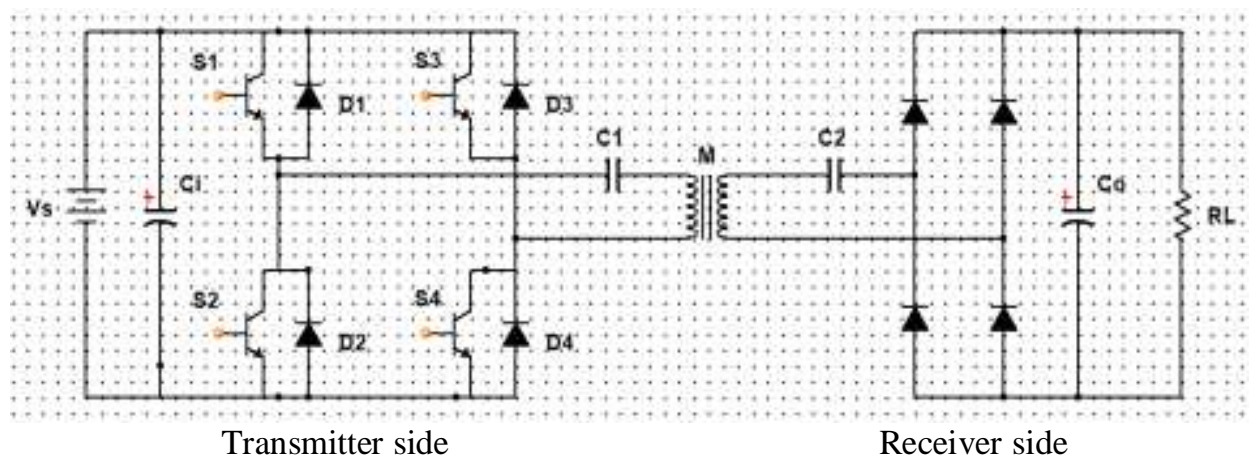

Figure 4. Equivalent circuit of the WPT system

This type of CT is able to minimize the voltage at the transmitter coil and concurrently, provide the load with constant voltage [37]. If the system utilizes the SS topology, the input voltage and efficiency are high at the maximum mutual inductance [27]. In contrast, if the system utilizes LCC-LCC topology, higher misalignment tolerance is expected at the minimum mutual inductance [31]. The total magnetic field or also known as the total flux that is produced by the transmitter coil is either entirely coupled or partially coupled to the receiver coil. The terms for this occurrence are tightly coupled coils if all flux is distributed and loosely coupled coils if the flux is partially distributed. Typically, the tightly coupled coils produced much larger mutual inductance, $\mathrm{M}$ than the leakage inductance. In [38], the coupling coefficient is approximately $92 \%$ to $98 \%$ for the tightly coupled coils such as induction motors and transformers. On the other hand, the loosely coupled coils may produce high leakage magnetic field if the coils are poorly coupled and commonly, the windings of the couplers are in the planar spiral form [39, 40].

\section{RELATED WORKS}

In the IPT system, various coil structures have existed due to the ongoing research for the best coupler geometry design with better efficiency of the overall system. Different coil geometries give different magnetic field distribution [41]. The diversity of coil geometries contributes to the founding of many types of couplers. Among the coupler designs are the CSC [40, 42-45], SC [36, 39, 46], RC [47-49] and DDC coils [17, 23, 50]. Over the years, some innovative coupler geometry designs have been proposed, for instance, bipolar coil (BC) $[51,52]$ and double-D quadrature coil (DDQC) [28]. Not limited to that, the mutual inductance, self-inductance, coupling coefficient, and misalignment variation are among the key factors that are affected by the coil geometry designs. The coil geometry designs further affect the PTE of the IPT system. With the aim of achieving better PTE, the authors of [42] put forward the idea of cancellation coil implementation with the main coil at both transmitter and receiver coils to minimize the electromagnetic field (EMF) outside the charging region.

R. A. Deshmukh and D. B. Talange [15] proposed the IPT system that is capable of transferring $1 \mathrm{~kW}$ power over $10 \mathrm{~cm}$ air-gap at $15 \mathrm{kHz}$ frequency with $95 \%$ efficiency. R. Vaka and R. Kumar [16] suggested an extended idea of asymmetrical CSC as the geometry design of the coupler coils. This design exhibits a better coupling coefficient and misalignment tolerance while having equal outer diameter but adjusted inner diameter with $120 \mathrm{~mm}$ air-gap for each case. On the other hand, G. Ke et al. [23] discussed the null coupling position 
for CSC to analyze the magnetic properties of the system. These researchers found out that the null coupling occurs when the lateral offset is approximately $50 \%$ of the outer diameter for the CSC. However, in recent findings by T. Fujita, H. Kishi, H. Uno et al. [53], the implementation of the solenoid coils rather than the CSC is addressed to improve the misalignment. Even though that is the case, CSC is still preferred because of its geometry that offers simpler geometry with perfect symmetry while able to control the coupling coefficient by controlling the physical sizes of the coupler geometries [40].

Other than CSC geometry, the SC and RC geometries are also common in the WPT system owing to the characteristics of their magnetic field that is single-sided [8]. The single-sided characteristics help with leakage flux reduction as its flux pattern, as shown in Figure 5(c), distribute most of the flux under the coils and away from the floor pan [54]. Consequently, it avoids the leakage flux from coupled into the vehicle, which may lead to undesirable efficiency loss [38]. In addition, the authors of [47, 48] agreed that RC geometry exhibits excellent tolerance to misalignment, as shown in Figure 8(b) and therefore, suitable for high power transmission. The SC and RC geometries notably possess quite similar characteristics as they have almost the same geometries. However, RC geometry is preferred as it offers greater magnetic field area even if they both operate using the same material and coil turns thus, offering much bigger charging region [22, 55].

Innovatively, in $[29,56]$, the authors recommended integrating the compensated coils with the main coils at both transmitter and receiver coils to enhance the PTE of the IPT system. The compensated coils are tested to be either unipolar or bipolar coils. Note that the bipolar coils mentioned in these references carry the meaning of polarized coils and not bipolar geometry design. The transmitter and receiver coils are desired to have high self-inductance and therefore, leads towards achieving high coupling coefficient, high mutual inductance and high misalignment tolerance when they are coupled $[57,58]$. The misalignment that occurs during the coil coupling reduces the PTE. Therefore, an effort offering a perfect alignment to improve the PTE using giant magnetoresistance (GMR) sensors were built in a study [59]. The authors designed the system to resolve the misalignment when the designated algorithm detects the suitable direction and magnitude that an EV required for coupling in alignment based on the results showed by the GMR sensors.

For EV application, the IPT system might encounter impedance matching problem with highfrequency circuits and achieving high PTE seems to be complicated. Therefore, to achieve greater PTE, the authors of [60] presented the impedance matching network (IMN) to optimize the transmitter coil track. $\mathrm{H}$. Dashora, G. Buja, M. Bertoluzzo et al. [61] have summarized the characteristics of compatible coil geometries that should be light, thin, and compact to avoid unnecessary additional weight to the EV. The charging system should have a satisfactory coupling coefficient to operate without any physical contact and also able to tolerate an acceptable misalignment with air-gap variation at least 150 to $200 \mathrm{~mm}$, especially when dynamically charging the EV [11, 53, 60, 62, 63]. In DWC application, DDC is commonly preferred for segmented rails rather than CSC due to its ability to deliver stronger coupling coefficient and greater offset tolerance [50]. Even if the CSC and DDC having similar materials and output power, DDC contributed a five times larger charging region compared to CSC [64]. A. A. S. Mohamed et al. [32] proposed the idea to enhance the DDC using the improved Tabu search algorithm. The flux distribution of the coils is simulated to further analyze the PTE wirelessly by DDC geometry. G. Ke et al. [23] discussed the null coupling position for DDC and found out that the null coupling occurs when the lateral offset is approximately $33.3 \%$ of the length of secondary coil for DDC. Yet, its geometry still experiences a dramatic drop when EV is moving from one transmitter to the next transmitter coil. This drop leads to failure in achieving good PTE as the mutual inductance is not stable and insufficiently strong.

Therefore, a crossed DDC geometry was investigated with its double-coil strategy [17]. The suggestion to design a well-functioning transmitter coil that should achieve low electric and magnetic values by attaining high efficiency and high output power is elaborated more in paper [17] where it results in the extended version of the rectangular coil. The mutual inductance profoundly influences the efficiency and output power of a WPT system. The mutual inductance should also be designed very well to be large and sufficient enough to attain the reasonable output power [15-17, 23, 32, 53]. Usually, the coil geometry of the inductive magnetic coupler for DWC is the extended rail architecture. However, this extended rail architecture has suffered from low efficiency and substantial electromagnetic interference. Fortunately, Oak Laboratory in the USA has developed a dynamic charging system using the array of the coil. This architecture successfully achieved lower electromagnetic compatibility and also reduced the values of the electric and magnetic field, and this makes the coil array more attractive and compatible to be implemented [11]. Besides, [62] has recently suggested the double-transmitting coil scheme to improve power fluctuation caused by the relative position changes effect in DWC.

\subsection{Circular spiral coil}

In the initial stage of WPT evolution, the circular spiral coil (CSC) was proposed for several years [39, 40, 43]. The typical CSC is as demonstrated in Figure 5(a). The magnetic flux of this coil geometry 
distributes in a cylindrical symmetry [39]. Therefore, due to its spiral geometry, this coil offers a high misalignment tolerance in all directions.

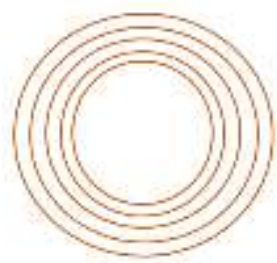

(a)

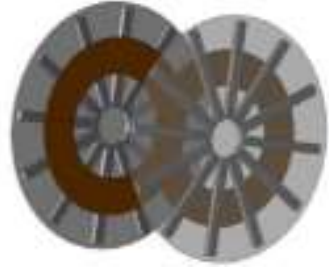

(b)

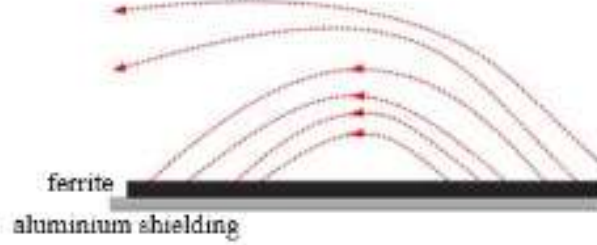

(c)

Figure 5. CSC (a) typical geometry, (b) with ferrite spokes [55] and (c) flux lines from front view

R. Deshmukh and D. Talange [15] discussed the procedures in designing a $1 \mathrm{~kW}$ power for the IPT system. The authors analyzed the magnetic parameters of the DWC inductive coupling coils which implement the circular spiral coil geometry at both sides, transmitter and receiver coils. The CSC is then introduced with the use of ferrite shown in Figure 5(b). The addition of ferrite at the back of the coil pad is to promote the flux path and together with that it may help in reducing the flux leakage. The IPT system needs suitable, and high frequency with proper compensation to achieve a reasonably high efficiency contributes to better system performance. The IPT system will give maximum output power when the operating frequency is similar or close to the resonant frequency. Hence, the capacitance and inductance at both transmitter and receiver coils need to be designed to match the system's resonant frequency [65].

However, the increase in operating frequency might result in a highly inductive circuit. Thus, it increases the impedance of the overall circuit [16]. This increment will result in reduced power factor as it approaches zero when the operating frequency grows. Therefore, since the load and WPT coil inductances are the factors affecting the power transfer, this will cause the transmitter coil to have a high VA rating and thus, reducing the efficiency of the overall system. However, R. Deshmukh and D. Talange [15] found that capacitive compensation in both transmitter and receiver coils is much recommended to magnify the operating frequency while improving the power factor by employing the CSC geometry. The CSC is well-known because of its excellent magnetic properties and electrical properties which results in its simplicity to experiment on [63]. It is the most utilized geometry for WPT, as mentioned in $[15,16,23]$ where the outer and inner diameter is decided from the current density of the material used.

\subsection{Square and rectangular coils}

Figure 6(a) demonstrates the typical geometry of the square coil (SC). The typical geometry of the rectangular coil (RC) is shown in Figure 6(b), and Figure 6(c) illustrates the RC with ferrite bars. For the SC with ferrite bars, the illustration is quite the same with the RC with ferrite bars, as shown in Figure 6(c). For the SC, the calculation for the magnetic field is quite different from the CSC in which, the magnetic field calculation for this coil geometry can be quite tricky since it involves four similar sides that are equal. Therefore, most commonly, the CSC is preferred because of more straightforward calculations.

In [46], the researchers have tried analyzing multi-single SC that enables the EV battery to charge from one $\mathrm{SC}$ to another $\mathrm{SC}$ which is along the track either with ferrite or directly air as their core. As expected, the power efficiency of the system increases when the coupled coils are made up of ferrite-cored rather than air-cored. However, SC is tested to has a sensitive misalignment tolerance when compared to the hexagonal coil geometry [36]. The SC is less preferred compared to the CSC and RC as most researchers only focus on the two other coil designs to be implemented in the WPT system. Practically speaking, the reason behind this is maybe due to the close similarity between the square and rectangular geometry features. Both coil geometries are supposed to have the same method of calculation because of their close resemblance in the form itself. However, since RC geometry has a more substantial area even if using the same length of wire that SC used, the power efficiency of the RC is found to be better. Based on a study conducted in [67], they found out that the bigger the coil size, the better the performance of power efficiency.

The RC geometry is suitable in the dynamic charging due to its high tolerance on misalignment [23] while capable of transferring power effectively and its cost-effectiveness [22, 47]. In the same case, as mentioned in the CSC section, the ferrite bar has been used and attached to the rectangular coil to optimize power efficiency. Some researchers had tested the IPT technique for a variety of misalignment that is possible on the rectangular coil to improve the coupling coefficient and mutual inductance between the two coupled 
coils [47]. In a study, it shows that the longer the ferrite bars, the higher power transfer compared to the shorter bar [66]. Therefore, power transfer is proven to increase with the addition of longer ferrite bars. Bilandžija et al. in their study, have proposed to analyze the uniformity of the magnetic field intensity that is produced by the RC geometry [48]. They later found the optimal distance or misalignment that their proposed RC can achieve. They used both the transversal and longitudinal sheets to represents the magnetic field intensity produced. However, due to the geometry of the RC, some areas have low magnetic field intensity as expected.

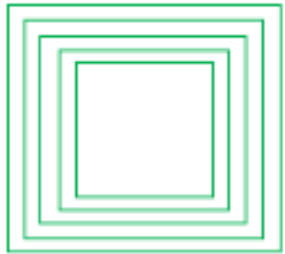

(a)

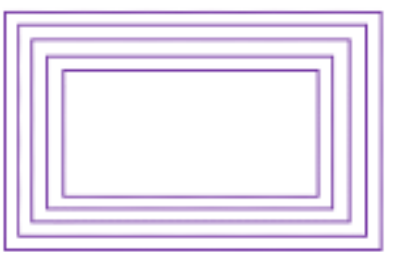

(b)

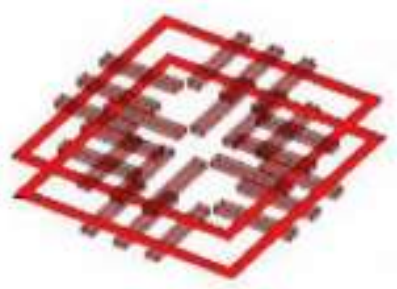

(c)

Figure 6. Geometry of the (a) typical SC, (b) typical RC and (c) RC with ferrite bars [66]

\subsection{Double-D Coil}

Figure 7(a) demonstrates the typical geometry of coreless double-D coil (DDC) and Figure 7(b) illustrates the DDC with ferrite bars. When discussing DDC, the geometry itself commonly made up of ferrite cores as the coils are placed at the top of ferrite, and this characteristic is referred to as polarized coil [61]. The origin existence of DDC is the results of the combination of flux pipe and CSC geometries advantages [54]. For more straightforward understanding, the DDC geometry is close to two equal rectangular geometry as in Figure 7(a) that connects magnetically in series with opposite current direction in each D coil [50].

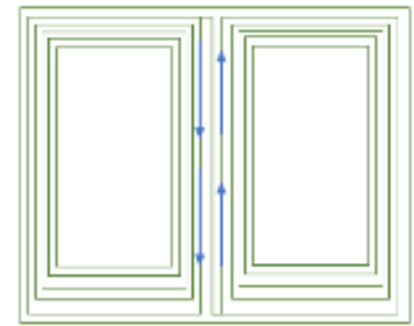

(a)



(b)

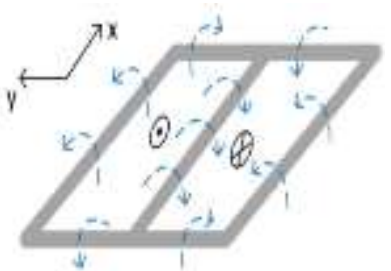

(c)

Figure 7. DDC (a) typical coreless geometry, (b) with ferrite bars and (c) flux line distribution

In addition, the coupling coefficient of this geometry declines smoothly compared to SC as it approaches zero with the displacement increment, as shown in Figure 8(a). Therefore, permitting a high PTE of the overall system, especially in DWC [11]. The selection of coil geometries differs for each application, and different researchers have to make efforts to optimize their coil geometry selection to achieve their conflicting goals. Therefore, the authors of [68] compared several coil geometry with similar power density to ensure a fair comparison of their coupling coefficient $(\mathrm{k})$ under different misalignment and air-gap as illustrated in Figure 8(b) and Figure 8(c). The higher the coupling coefficient over the displacement, misalignment or airgap, the higher the efficiency that particular geometry can offer. 


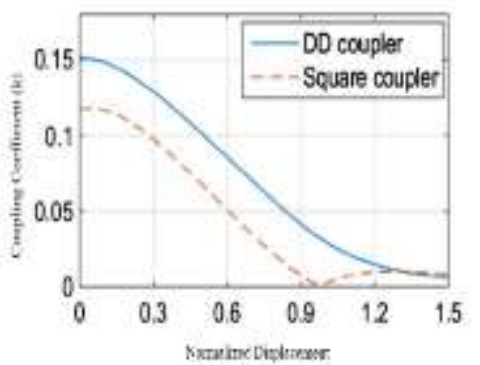

(a)

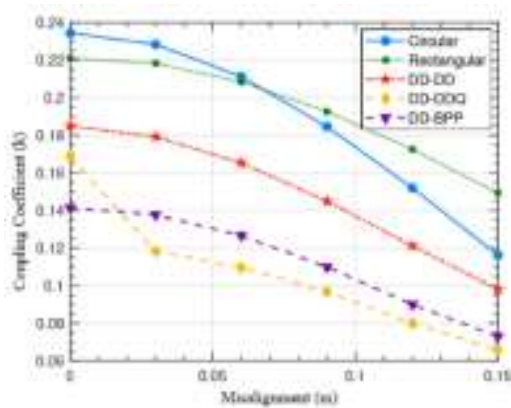

(b)



(c)

Figure 8: Coupling Coefficient (a) vs. Displacement [61], (b) vs. Misalignment [68] and (c) vs. Air-Gap [68]

\section{DISCUSSION}

The basic coil designs discussed have their benefits to the IPT system. After all, these basic coil designs are easy to operate because of its geometry. Not limited to that, these basic coil designs are the ones that triggered the development of other coil geometry designs that the WPT system has up until recently. When the coupled coils are in perfect alignment, the overall maximum power efficiency is expected. However, the all-time concerns when speaking of coupled coils are, of course, the misalignment tolerance and power efficiency. Both of these concerns are affected by the coupling coefficient and mutual inductance of the overall WPT system. Most commonly, adding ferrite bars or ferrite in any shape has managed to facilitate the PTE to be much better when compared to the air-cored or coreless coupled coil. Transmission of power by electromagnetic induction between the transmitter and receiver coils is possible when several aspects are given attention to design such a wireless technology.

The aspects that require observation in designing the coils for the WPT system are such as:

- Geometry design of the coil including the coil number of turns, layer number of turns and spacing between the turns or commonly referred to as pitch

- Type of wire used either the copper wire or Litz wire of any AWG that best suited the application's goal

- Obey the bifurcation-free criteria by using the suitable Litz wire and proper operating frequency that is the best if it is closer to the resonant frequency

Commonly, copper is selected as the material for designing the coil because of its better conductivity and lower price despite other materials. Also, less voltage is required to produce a sufficient magnetic field if copper is used. Thus, the heat of the coil could also reduce significantly. However, with the use of solid conductor, induced eddy current undesirable effects such as skin effect and proximity effect are dominant and therefore, affecting the WPT efficiency. Feeding the coils with high-frequency voltage will result in a highfrequency current flows through the coil. Due to this so-called time-varying current, the time-varying magnetic field is produced and results in induced eddy current.

Consequently, to reduce the losses caused by eddy current, a bunch of stranded wires at a high frequency such as Litz wire is recommended to be used [18]. Litz wire is made of several thin strands that are insulated, and it is the best suitable option to improve the WPT efficiency with its less resistance value. However, another aspect which is bifurcation is considered worrisome if it happens during the designing process. Bifurcation is an occurrence of more than one zero phase angle frequency in a circuit. The WPT system is supposed to operate at the resonance frequency, which means the value should be zero if the power efficiency is to be improved. Therefore, to improve the PTE, R. A. Deshmukh and D. B. Talange [15] has concluded that it also depends on the quality factor, $\mathrm{Q}$ and coupling coefficient, $\mathrm{k}$. These factors are determined by not only coil geometry, core material and coupler distance, but also, the self-inductance of the coils must be high with low series resistance to attain high $\mathrm{Q}$ and $\mathrm{k}$ [8]. Table 2 summarizes the advantages and limitations of related works. 
Table 2. Summary table of related works

\begin{tabular}{|c|c|c|c|c|c|}
\hline Ref. & Authors & Description & Coil Dimensions & Advantages & Limitations \\
\hline$[42]$ & $\begin{array}{l}\text { A. Tejeda et } \\
\text { al. (2016) }\end{array}$ & $\begin{array}{l}\text { Proposed the utilization of an } \\
\text { inductive cancellation coil } \\
\text { that connected in series- } \\
\text { opposing with the transmitter } \\
\text { (main) coil to reduce the EMF } \\
\text { outside the charging region }\end{array}$ & $\begin{array}{c}\text { Transmitter and cancellation coil } \\
\text { inner diameter and outer } \\
\text { diameter, respectively: } \\
357.2 \mathrm{~mm} \text { and } 500 \mathrm{~mm} \\
\text { Transmitter (cancellation) coil } \\
\text { number of turns: } 9 \text { (3) }\end{array}$ & $\begin{array}{l}\text { - Suggested cancellation } \\
\text { coil is good enough as it } \\
\text { was able to transfer } \\
\text { more power with less } \\
\text { stray leakage and low } \\
\text { impact on the coupling } \\
\text { factors }\end{array}$ & $\begin{array}{l}\text { - No comparison is } \\
\text { made in terms of } \\
\text { overall efficiency } \\
\text { and power losses } \\
\text { with a similar } \\
\text { geometry consists of } \\
\text { ferrite }\end{array}$ \\
\hline [36] & $\begin{array}{l}\text { E. Aydin et al. } \\
\text { (2018) }\end{array}$ & $\begin{array}{l}\text { Inspected the comparison of } \\
\text { the square coil and hexagonal } \\
\text { coil for the misalignment } \\
\text { tolerance }\end{array}$ & $\begin{array}{c}\text { Square coil sides length: } 212 \\
\text { mm } \\
\text { Hexagonal coil sides length: } 132 \\
\text { mm }\end{array}$ & $\begin{array}{l}\text { - The intended coil } \\
\text { geometry has a } \\
\text { transmission power of } \\
2.2 \mathrm{~kW} \text { for charging }\end{array}$ & $\begin{array}{l}\text { - The square coil is } \\
\text { more sensitive to } \\
\text { misalignment } \\
\text { compared to } \\
\text { hexagonal coil }\end{array}$ \\
\hline$[17]$ & $\begin{array}{l}\text { L. Xiang et al. } \\
\qquad(2018)\end{array}$ & $\begin{array}{l}\text { Suggested the crossed DD } \\
\text { coil structure and put forward } \\
\text { the idea of using the double- } \\
\text { coil excitation method }\end{array}$ & $\begin{array}{l}\text { Transmitter coil: } \\
1000 \mathrm{~mm} \text { x } 250 \mathrm{~mm} \\
\text { Receiver coil: } \\
500 \mathrm{~mm} \text { x } 400 \mathrm{~mm}\end{array}$ & $\begin{array}{l}\text { - Lessen the power } \\
\text { fluctuation with the } \\
\text { efficiency variation from } \\
89.2 \% \text { to } 88.7 \% \\
\text { regardless of EV } \\
\text { positions }\end{array}$ & $\begin{array}{l}\text { - Implementation of } \\
\text { the suggested coil } \\
\text { structure is only for } \\
\text { the transmitter coil }\end{array}$ \\
\hline [29] & $\begin{array}{l}\text { T. Kan et al. } \\
\text { (2018) }\end{array}$ & $\begin{array}{l}\text { Integration of bipolar coils as } \\
\text { the compensated coils into the } \\
\text { unipolar coils as the main } \\
\text { transmitter and receiver coil } \\
\text { structures }\end{array}$ & $\begin{array}{c}\text { Transmitter coil: } \\
600 \mathrm{~mm} \text { x } 450 \mathrm{~mm} \text { x } 4 \mathrm{~mm} \\
\text { Receiver coil: } \\
400 \mathrm{~mm} \text { x } 300 \mathrm{~mm} \text { x } 4 \mathrm{~mm}\end{array}$ & $\begin{array}{l}\text { - Good performance on } \\
\text { front-to-rear } \\
\text { misalignment and air- } \\
\text { gap with } 95.49 \% \text { dc-dc } \\
\text { efficiency }\end{array}$ & $\begin{array}{l}\text { - The coil structures } \\
\text { introduced } \\
\text { additional weight to } \\
\text { EV }\end{array}$ \\
\hline$[47]$ & $\begin{array}{l}\text { S. Rao et al. } \\
\text { (2019) }\end{array}$ & $\begin{array}{l}\text { Investigated the coupling } \\
\text { coefficient, mutual inductance } \\
\text { and flux distribution of } \\
\text { rectangular coil }\end{array}$ & $\begin{array}{l}\text { Transmitter and receiver coils: } \\
152 \mathrm{~mm} \times 132 \mathrm{~mm} \\
\text { Transmitter and receiver coils } \\
\text { number of turns: } \\
20 \text { turns }\end{array}$ & $\begin{array}{l}\text { - The related parameters } \\
\text { are tested with various } \\
\text { misalignment for air and } \\
\text { ferrite cored }\end{array}$ & $\begin{array}{l}\text { - The analysis is } \\
\text { done for one } \\
\text { dimension of the } \\
\text { rectangular coil }\end{array}$ \\
\hline$[45]$ & $\begin{array}{l}\text { M. S. Alam } \\
\text { Chowdhury } \\
\text { and X. Liang } \\
\quad(2019)\end{array}$ & $\begin{array}{l}\text { Anticipated the combination } \\
\text { of the circular and double-D } \\
\text { (DD) coils structure where } \\
\text { the two different geometry } \\
\text { coils are electrically } \\
\text { connected in parallel }\end{array}$ & $\begin{array}{l}\text { Coil dimensions as } \\
\text { recommended in SAE J2954 }\end{array}$ & $\begin{array}{l}\bullet \text { Better magnetic } \\
\text { coupling was shown by } \\
\text { the combination of the } \\
\text { proposed coil when } \\
\text { compared with the } \\
\text { conventional coils }\end{array}$ & $\begin{array}{l}\text { - The performance } \\
\text { metrics are only for } \\
\text { the specifications } \\
\text { suggested by SAE } \\
\text { J2954 }\end{array}$ \\
\hline$[60]$ & $\begin{array}{l}\text { L. Tan et al. } \\
\text { (2020) }\end{array}$ & $\begin{array}{l}\text { Presented a WPT system that } \\
\text { optimizes the transmitting } \\
\text { coil track with impedance } \\
\text { matching network (IMN) }\end{array}$ & $\begin{array}{l}\text { Transmitter coil: } \\
10000 \mathrm{~mm} \text { x } 150 \mathrm{~mm} \\
\text { Receiver coil: } \\
150 \mathrm{~mm} \times 150 \mathrm{~mm}\end{array}$ & $\begin{array}{l}\text { - A constant reflected } \\
\text { load resistance together } \\
\text { with the maximum } \\
\text { speed limit is achieved } \\
\text { from transmitter length } \\
\text { selection and IMN }\end{array}$ & $\begin{array}{l}\text { - The system is } \\
\text { tested for } 2 \mathrm{~mm} \text { air- } \\
\text { gap only }\end{array}$ \\
\hline$[62]$ & $\begin{array}{l}\text { S. Li et al. } \\
(2020)\end{array}$ & $\begin{array}{c}\text { Suggested double- } \\
\text { transmitting coil scheme to } \\
\text { improve the relative position } \\
\text { changes effect }\end{array}$ & $\begin{array}{l}\text { Transmitter coil: } \\
720 \mathrm{~mm} \text { x } 270 \mathrm{~mm} \\
\text { Receiver coil: } \\
360 \mathrm{~mm} \times 360 \mathrm{~mm}\end{array}$ & $\begin{array}{l}\text { - Suggested WPT } \\
\text { system was able to } \\
\text { restrain the power } \\
\text { fluctuation experienced } \\
\text { in DWC } \\
\end{array}$ & $\begin{array}{l}\text { - The system is } \\
\text { tested for } 105 \mathrm{~mm} \\
\text { air-gap only }\end{array}$ \\
\hline
\end{tabular}

\section{CONCLUSION}

A brief review of the basic coil designs for the WPT system is carried out. The basic coil designs to implement the power transmission wirelessly are investigated and discussed together with the key factors affecting the design considerations. It has been shown that different coil geometry designs have their contribution to the IPT charging system. The key parameters influence the overall system regardless of their coil geometries has also been evaluated. Also, the evaluation of the comparative analysis of different geometries efficiency is done. Thus, it is hoped that this brief review manages to offer an understanding of the basic coil geometries discussed as the conventional designs of the WPT system.

\section{ACKNOWLEDGEMENTS}

This research work has partially supported by the IIUM Flagship Grant, number IRF19-026-0026 under the Malaysia Ministry of Higher Education Malaysia. 


\section{REFERENCES}

[1] G. A. Covic and J. T. Boys, "Inductive Power Transfer," in Proceedings of the IEEE, 2013, vol. 101, no. 6, pp. 1276-1289, doi: 10.1109/JPROC.2013.2244536.

[2] P. Bauer, "Future of EV Charging," in 2019 International Aegean Conference on Electrical Machines and Power Electronics (ACEMP) \& 2019 International Conference on Optimization of Electrical and Electronic Equipment (OPTIM), pp. 8-9, 2019. doi: 10.1109/ACEMP-OPTIM44294.2019.9007203.

[3] Y. D. Ko and Y. J. Jang, "The Optimal System Design of the Online Electric Vehicle Utilizing Wireless Power Transmission Technology," IEEE Trans. Intell. Transp. Syst., vol. 14, no. 3, pp. 1255-1265, 2013.

[4] L. Huang and A. P. Hu, "Defining the Mutual Coupling of Capacitive Power Transfer for Wireless Power Transfer," Electron. Lett., vol. 51, no. 22, pp. 1806-1807, 2015. doi: 10.1049/el.2015.2709.

[5] D. Vincent, P. S. Huynh, L. Patnaik and S. S. Williamson, "Prospects of Capacitive Wireless Power Transfer (CWPT) for Unmanned Aerial Vehicles,"2018 IEEE PELS Work. Emerg. Technol. Wirel. Power Transf., pp. 1-5, 2018.

[6] G. G. Silva and C. A. Petry, "Capacitive Wireless Power Transfer System Applied to Low-Power Mobile Device Charging," Int. J. Electr. Energy, vol. 3, no. 4, pp. 230-234, 2015, doi: 10.18178/ijoee.3.4.230-234.

[7] A. Elekhtiar, L. Eltagy, T. Zamzam, and A. Massoud, "Design of A Capacitive Power Transfer System for Charging of Electric Vehicles," 2018 IEEE Symp. Comput. Appl. Ind. Electron., pp. 150-155, 2018.

[8] D. Patil, S. Member, M. Mcdonough, J. Miller, and L. Fellow, "Wireless Power Transfer for Vehicular Applications : Overview and Challenges," IEEE Trans. Transp. Electrif., vol. 7782, no. c, pp. 1-35, 2017,

[9] T. Mizuno, S. Yachi, A. Kamiya, and D. Yamamoto, "Improvement in Efficiency of Wireless Power Transfer of Magnetic," IEEE Trans. Magn., vol. 47, no. 10, pp. 4445-4448, 2011.

[10] W. Yan and J. Chen, "A General Design of Magnetic Coupling Resonant Wireless Power Transmission Circuit," 3rd Int. Conf. Adv. Energy, Environ. Chem. Eng. -IOP Conf. Ser. Earth Environ. Sci., vol. 69, pp. 1-8, 2017.

[11] J. M. Miller, P. T. Jones, J. Li, and O. C. Onar, "ORNL Experience and Challenges Facing Dynamic Wireless Power Charging of EV's," IEEE Circuits Syst. Mag., vol. 15, no. 2, pp. 40-53, 2015. doi: 10.1109/MCAS.2015.2419012.

[12] K. Na, H. Jang, H. Ma, and F. Bien, "Tracking Optimal Efficiency of Magnetic Resonance Wireless Power Transfer System for Biomedical Capsule Endoscopy," IEEE Trans. Microw. Theory Tech., vol. 63, no. 1, pp. 295-303, 2015,

[13] N. P. Suh, D. H. Cho, and C. T. Rim, "Design of On-Line Electric Vehicle (OLEV)," Springer, pp. 3-8, 2011,

[14] S. Ahn and J. Kim, "Magnetic Field Design for High Efficient and Low EMF Wireless Power Transfer in On-Line Electric Vehicle," Proceedings of the 5th European Conference on Antennas and Propagation (EUCAP), pp. 3979-3982, 2011.

[15] R. A. Deshmukh and D. B. Talange, "Design of 1 kW Inductive Power Transfer System for Electric Vehicle," 2015 International Conference on Technological Advancements in Power and Energy (TAP Energy), pp. 93-97, 2015.

[16] R. Vaka and R. Kumar, "Design Considerations for Enhanced Coupling Coefficient and Misalignment Tolerance using Asymmetrical Circular Coils for WPT System," Arab. J. Sci. Eng., 2018, doi: 10.1007/s13369-018-3219-x.

[17] L. Xiang, X. Li, J. Tian, and Y. Tian, "A Crossed DD Geometry and Its Double-Coil Excitation Method for Electric Vehicle Dynamic Wireless Charging Systems," IEEE Access, vol. 6, pp. 45120-45128, 2018.

[18] G. Southern et al., "Electric Vehicles Wireless Power Transfer State-of-The-Art," Energy Procedia, vol. 162, pp. 24-37, 2019, doi: 10.1016/j.egypro.2019.04.004.

[19] M. Yilmaz and P. T. Krein, "Review of Battery Charger Topologies, Charging Power Levels, and Infrastructure for Plug-In Electric and Hybrid Vehicles," IEEE Trans. Power Electron., vol. 28, no. 5, pp. 2151-2169, 2013.

[20] Sarwat A.I., Sundararajan A., Parvez I., Moghaddami M., Moghadasi A., "Toward a Smart City of Interdependent Critical Infrastructure Networks,” In: Amini M., Boroojeni K., Iyengar S., Pardalos P., Blaabjerg F., Madni A. (eds) Sustainable Interdependent Networks. Studies in Systems, Decision and Control, vol 145. Springer, Cham, 2018.

[21] J. M. Miller, O. C. Onar, and M. Chinthavali, "Primary-Side Power Flow Control of Wireless Power Transfer for Electric Vehicle Charging," IEEE J. Emerg. Sel. Top. Power Electron., vol. 3, no. 1, pp. 147-162, 2015,

[22] W. Chen, C. Liu, C. H. T. Lee, and Z. Shan, "Cost-Effectiveness Comparison of Coupler Designs of Wireless Power Transfer for Electric Vehicle Dynamic Charging," Energies, vol. 9, pp. 1-13, 2016, doi: 10.3390/en9110906.

[23] G. Ke, Q. Chen, L. Xu, S. Wong and C. K. Tse, "A model for coupling under coil misalignment for DD pads and circular pads of WPT system," 2016 IEEE Energy Conversion Congress and Exposition (ECCE), 2016, pp. 1-6.

[24] C. Fang, J. Song, L. Lin and Y. Wang, "Practical considerations of series-series and series-parallel compensation topologies in wireless power transfer system application," 2017 IEEE PELS Workshop on Emerging Technologies: Wireless Power Transfer (WoW), Chongqing, 2017, pp. 255-259, doi: 10.1109/WoW.2017.7959404.

[25] K. Aditya, S. Member, S. S. Williamson, and S. Member, "Comparative Study of Series-Series and Series-Parallel Topology for Long Track EV Charging Application," 2014 IEEE Transp. Electrif. Conf. Expo., pp. 1-5, 2014.

[26] K. Aditya and S. S. Williamson, "Comparative study of Series-Series and Series-Parallel compensation topologies for electric vehicle charging," 2014 IEEE 23rd International Symposium on Industrial Electronics (ISIE), Istanbul, 2014, pp. 426-430. 
[27] M. A. Houran, X. Yang, and W. Chen, "Magnetically Coupled Resonance WPT : Review of Compensation Topologies , Resonator Structures with Misalignment, and EMI Diagnostics," Electronics, pp. 1-45, 2018.

[28] N. Rasekh and M. Mirsalim, "Evaluation Study on an Integration Method for a DDQP using LCC and Series Compensation Topologies for Inductive Power Transfer," IET Electr. Power Appl., 2018.

[29] T. Kan, F. Lu, T. Nguyen, P. P. Mercier, and C. C. Mi, "Integrated Coil Design for EV Wireless Charging Systems Using LCC Compensation Topology," IEEE Trans. Power Electron., vol. 33, no. 11, pp. 9231-9241, 2018.

[30] G. Jung, S. Jeon, D. Cho, and S. Member, "Design and Implementation of Shaped Magnetic-Resonance-Based Wireless Power Transfer System for Roadway-Powered Moving Electric Vehicles," IEEE Trans. Ind. Electron., vol. 61, no. 3, pp. 1179-1192, 2014.

[31] W. Zhang, S. Member, and C. C. Mi, "Compensation Topologies of High-Power Wireless Power Transfer Systems," IEEE Trans. Veh. Technol., vol. 65, no. 6, 2015.

[32] A. A. S. Mohamed, S. An and O. Mohammed, "Coil Design Optimization of Power Pad in IPT System for Electric Vehicle Applications," in IEEE Transactions on Magnetics, vol. 54, no. 4, pp. 1-5, April 2018, Art no. 9300405.

[33] J. T. Boys and G. A. Covic, "IPT Fact Sheet Series : No . 2 Magnetic Circuits for Powering Electric Vehicles," Qualcomm Fact Sheet, no. 2, 2014.

[34] Y. Zhang, Z. Yan, T. Kan, and C. Mi, "Interoperability Study of Fast Wireless Charging and Normal Wireless Charging of Electric Vehicles with a Shared Receiver," IET Power Electron., vol. 12, no. 10, pp. 2551-2558, 2019.

[35] V. T. Nguyen, S. D. Yu, S. W. Yim, and K. Park, "Optimizing Compensation Topologies for Inductive Power Transfer at Different Mutual Inductances," in 2017 IEEE PELS Workshop on Emerging Technologies: Wireless Power Transfer, WoW 2017, 2017, pp. 153-156.

[36] E. Aydin, Y. Kosesoy, E. Yildiriz, and M. T. Aydemir, "Comparison of Hexagonal and Square Coils for Use in Wireless Charging of Electric Vehicle Battery," 2018 Int. Symp. Electron. Telecommun., pp. 1-4, 2018.

[37] W. Zhang, S. Member, S. Wong, S. Member, C. K. Tse, and Q. Chen, "Design for Efficiency Optimization and Voltage Controllability of Series-Series Compensated Inductive Power Transfer Systems," IEEE Trans. Power Electron., vol. 29, no. 1, pp. 191-200, 2014.

[38] A. Zaheer, M. Budhia, D. Kacprzak, G. A. Covic, and S. M. Ieee, "Magnetic Design of a 300 W Under-floor Contactless Power Transfer System," IECON 2011 - 37th Annu. Conf. IEEE Ind. Electron. Soc., pp. 1408-1413, 2011.

[39] Z. Luo and X. Wei, "Analysis of Square and Circular Planar Spiral Coils in Wireless Power Transfer System for Electric Vehicles," IEEE Trans. Ind. Electron., vol. 65, no. 1, pp. 331-341, 2018.

[40] Y. Wang, W. Liu, and Y. Xie, "Design and Optimization for Circular Planar Spiral Coils in Wireless Power Transfer System," 2019 22nd Int. Conf. Electr. Mach. Syst., pp. 1-4, 2019.

[41] B. M. Mosammam, N. Rasekh, M. Mirsalim and J. S. Moghani, "Comparative Analysis of the Conventional Magnetic Structure Pads for the Wireless Power Transfer Applications," 2019 10th International Power Electronics, Drive Systems and Technologies Conference (PEDSTC), Shiraz, Iran, 2019, pp. 624-628.

[42] A. Tejeda, C. Carretero, J. T. Boys, and A. Covic, "Ferrite-less Circular Pad with Controlled Flux Cancellation for EV Wireless Charging," IEEE Trans. Power Electron., vol. 32, no. 11, pp. 8349-8359, 2016.

[43] D. Kim, S. Member, J. Kim, and Y. Park, "Optimization and Design of Small Circular Coils in a Magnetically Coupled Wireless Power Transfer System in the Megahertz Frequency," IEEE Trans. Microw. Theory Tech., vol. 64, no. 8, pp. 2652-2663, 2016.

[44] M. Budhia, S. Member, G. A. Covic, S. Member, and J. T. Boys, "Design and Optimization of Circular Magnetic Structures for Lumped Inductive Power Transfer Systems," IEEE Trans. Power Electron., vol. 26, no. 11, pp. 30963108, 2011.

[45] M. S. Alam Chowdhury and X. Liang, "Design of a Ferrite-Less Power Pad for Wireless Charging Systems of Electric Vehicles," in 2019 IEEE Canadian Conference of Electrical and Computer Engineering (CCECE), pp. 1-4, 2019.

[46] P. S. R. Nayak, G. Peddanna, K. Kamalapathi, and B. K. Naick, "Analysis of Mutual Inductance Between MultiSingle Coupled Coils at Square Structure using FEM," in 1st International Conference on Electrical, Control and Instrumentation Engineering (ICECIE), pp. 1-6, 2019.

[47] S. Rao, N. Panugothu, P. Gundugallu, T. Manikandan, D. Ekalavya, and S. P. Simon, "Analysis of Mutual Inductance Between Rectangular Structured Wireless Coupled Coils with Different Misalignments Using Finite Element Modeling," 2019 Natl. Power Electron. Conf., pp. 1-5, 2019.

[48] D. Bilandžija, D. Vinko, and I. Biondiü, "Achieving Uniform Magnetic Field with Rectangular Coil in Wireless Power Transmission System," 61st Int. Symp. ELMAR-2019, Zadar, Croat., no. September, pp. 23-25, 2019.

[49] F. J. López-Alcolea, J. Vázquez, P. Roncero-sánchez, and A. P. Torres, "Modeling of a Magnetic Coupler Based on Single- and Double-Layered Rectangular Planar Coils With In-Plane Misalignment for Wireless Power Transfer," IEEE Trans. Power Electron., vol. 35, no. 5, pp. 5102-5121, 2020. 
[50] B. M. Mosammam, N. Rasekh, M. Mirsalim, and A. Khorsandi, "Electromagnetic Analysis for DD Pad Magnetic structure of a Wireless Power Transfer (WPT) for Electrical Vehicles," 2018 Smart Grid Conf., pp. 1-6, 2018.

[51] J. Deng, W. Li, S. Member, and T. D. Nguyen, "Compact and Efficient Bipolar Coupler for Wireless Power Chargers : Design and Analysis," IEEE Trans. Power Electron., vol. 30, no. 11, pp. 6130-6140, 2015.

[52] A. Zaheer, G. A. Covic, and D. Kacprzak, "A Bipolar Pad in A 10-kHz 300-W Distributed IPT System for AGV Applications," IEEE Trans. Ind. Electron., vol. 61, no. 7, pp. 3288-3301, 2014.

[53] T. Fujita, H. Kishi, H. Uno, and Y. Kaneko, "A Real-Car Experiment of a Dynamic Wireless Power Transfer System Based on Parallel-Series Resonant Topology," World Electr. Veh. J., vol. 10, no. 49, pp. 1-12, 2019.

[54] M. Budhia, S. Member, J. T. Boys, G. A. Covic, and S. Member, "Development of a Single-Sided Flux Magnetic Coupler for Electric Vehicle IPT Charging Systems, "IEEE Trans. Ind. Electron., vol. 60, no. 1, pp. 318-328, 2013.

[55] C. Liu and C. Jiang, "Overview of Coil Designs for Wireless Charging of Electric Vehicle," IEEE Conf. Pap., pp. 1-6, 2017.

[56] T. Kan, T. Nguyen, J. C. White, R. K. Malhan, and C. C. Mi, "A New Integration Method for an Electric Vehicle Wireless Charging System Using LCC Compensation Topology: Analysis and Design," IEEE Trans. Power Electron., vol. 32, no. 2, pp. 1638-1650, 2017.

[57] S. Chopra and P. Bauer, "Analysis and Design Considerations for a Contactless Power Transfer System," in 2011 IEEE 33rd International Telecommunications Energy Conference (INTELEC), Amsterdam, pp. 1-6, 2011.

[58] C. Wang, O. H. Stielau, G. A. Covic, and S. Member, "Design Considerations for a Contactless Electric Vehicle Battery Charger," IEEE Trans. Ind. Electron., vol. 52, no. 5, pp. 1308-1314, 2005.

[59] T. V Jeshma and B. George, "MR Sensor-Based Coil Alignment Sensing System for Wirelessly Charged EVs, "IEEE Sens. J., vol. 20, no. 10, pp. 5588-5596, 2020.

[60] L. Tan, W. Zhao, H. Liu, J. Li, and X. Huang, "Design and Optimization of Ground-Side Power Transmitting Coil Parameters for EV Dynamic Wireless Charging System," IEEE Access, vol. 8, 2020,

[61] H. K. Dashora, G. Buja, M. Bertoluzzo, and V. Lopresto, "Analysis and Design of DD Coupler for Dynamic Wireless Charging of Electric Vehicles," J. Electromagn. Waves Appl., pp. 1-20, 2017.

[62] S. Li, L. Wang, Y. Guo, C. Tao, and L. Ji, "Power Stabilization With Double Transmitting Coils and T-Type Compensation Network for Dynamic Wireless Charging of EV," IEEE J. Emerg. Sel. Top. Power Electron., vol. 8, no. 2, pp. 1801-1812, 2020.

[63] S. A. Zaini, S. H. Yusoff, A. A. Abdullah, S. Khan, F. Abd Rahman, and N. N. Nanda, "Investigation of Magnetic Properties for Different Coil Sizes of Dynamic Wireless Charging Pads for Electric Vehicles (EV)," IIUM Eng. J., vol. 21, no. 1, pp. 23-32, 2020.

[64] S. Li and C. C. Mi, "Wireless Power Transfer for Electric Vehicle Applications," IEEE J. Emerg. Sel. Top. Power Electron., vol. 3, no. 1, pp. 4-17, 2015.

[65] Y. Guo, L. Wang, Q. Zhu, C. Liao, and L. Wang, "Effects of Operation Frequency and Current on Coil Impedance of EV Wireless Charging System," Asia-Pacific Int. Symp. Electromagn. Compat. APEMC 2016, no. 51507168, pp. 71-73, 2016.

[66] Q. D. O. V. L. V Ri, R. Wr, S. Wkh, E. Dqg, U. D. Orqjhu, and O. F. Foh, "Analysis of Rectangular EV Inductive Charging Coupler," IEEE, pp. 285-291, 2017.

[67] L. Chen, S. Liu, Y. C. Zhou, and T. J. Cui, "An Optimizable Circuit Structure for High-Efficiency Wireless Power Transfer," IEEE Trans. Ind. Electron., vol. 60, no. 1, pp. 339-349, 2013.

[68] S. Bandyopadhyay, J. Dong, Z. Qin, and P. Bauer, "Comparison of Optimized Chargepads for Wireless EV Charging Application," 2019 10th International Conference on Power Electronics and ECCE Asia (ICPE 2019 - ECCE Asia), 2019, no. July, pp. 1-8.

\section{BIOGRAPHIES OF AUTHORS}

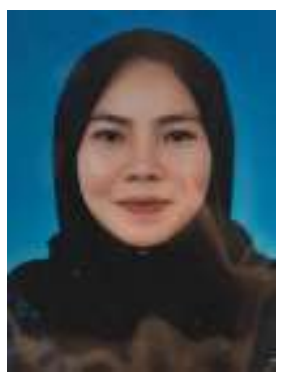

Nadia Nazieha Nanda received the BE degree in Communication Engineering from the International Islamic University Malaysia (IIUM), in June 2019. Since September 2019, she pursues her study as a Master student at the IIUM's Department of Electrical and Computer Engineering, (Master's in Science of Computer and Information-Electronics Engineering). She currently works on her project related to the wireless charging that includes the designing of the coil and the magnetic coupling of the coil. Her research involves the simulations of the coil design by using the Multisims software and the magnetic flux density of the designed coil by using the JMAG Designer software for inductive wireless charging. Her area of interest is coupling coil and power transfer efficiency. 

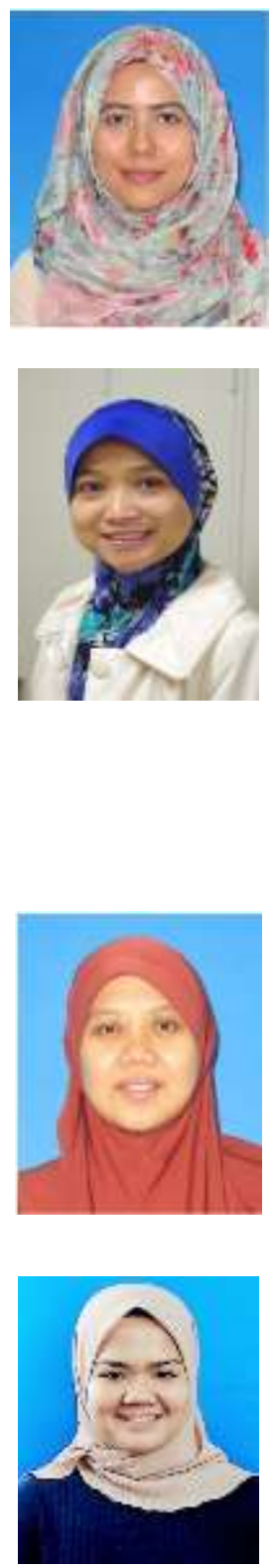

Siti Hajar Yusoff received the M.Eng. degree in electrical engineering (First Class Honors) and a $\mathrm{PhD}$ degree in electrical engineering from the University of Nottingham, UK, in 2009 and 2014, respectively. In 2015, she became an Assistant Professor in the Department of Electrical and Computer Engineering at International Islamic University Malaysia, Gombak. She is now a lecturer in control of power electronics systems and electrical power systems. Her research interests include control of power converters and drives, Matrix and multilevel converters, IoT, smart meter, wireless power transfer for dynamic charging in Electric Vehicle (EV), and renewable energy.

Siti Fauziah Toha (B.Eng' 03-M'06-PhD'10), is currently an Associate Professor at the Department of Mechatronics Engineering, International Islamic University Malaysia (IIUM). She received B. Eng (Hons) in Electrical and Electronics Engineering from University Technology Petronas and later received MSc from Universiti Sains Malaysia in electrical engineering. She was then completed her $\mathrm{PhD}$ in Automatic Control and Systems Engineering from The University of Sheffield in 2010. She later joined the Perusahaan Otomobil Nasional Berhad (PROTON) Malaysia as expert control consultant, working with vehicle hardware-in-loop for electric vehicle development. Her current research interest is a battery management system, energy reduction for electric motorcycle development as well as hybrid renewable energy applications using computational intelligence methods such as Genetic Algorithms, Fuzzy Logic and Particle Swarm optimization. Dr Toha is a senior member of IEEE and also a Professional Engineer in Malaysia as well as a Chartered Engineer with Engineering Council, The Institution of Engineering and Technology, United Kingdom. She is also an active member of Young Scientist Network, Academy of Sciences Malaysia (YSN-ASM).

Nurul Fadzlin Hasbullah is currently an Associate Professor at the Department of Electrical and Computer Engineering, Faculty of Engineering. She graduated with a First Class Honours from Cardiff University, Wales, with a Bachelor of Engineering in 2001. Later, she worked as an Integrated Chip Design Engineer in Malaysia Microelectronics Solution, Cyberjaya for a year before joining academia, teaching at the University Tenaga Nasional (Bangi, Malaysia) as a tutor. In 2003, she moved to International Islamic University Malaysia as an Assistant Lecturer. She obtained her PhD from the University of Sheffield, UK in 2010 researching on the electrical and optical characteristics of quantum dot laser structures. Her research interests continue in the areas of semiconductor device characterization, optical detectors and radiation hard devices.

Nur Amelia Shafina Roszaidie received Electronics-Computer and Information degree from International Islamic University Malaysia (IIUM) in the year 2019. She is currently pursuing a master's degree in Computer and Information Engineering at IIUM. During the degree, she worked on a smart power meter system using Raspberry Pi that includes the Internet of Things (IoT). In master, she is currently involved in the design of ferrite core geometry for the inductive wireless power transfer system. 